\title{
Editorial
}

\section{Current Management of Optic Nerve Injury}

\author{
Vivek Tandon ${ }^{1}$ Ashok Kumar Mahapatra ${ }^{1}$ \\ ${ }^{1}$ Department of Neurosurgery, All India Institute of Medical \\ Sciences, New Delhi, India \\ Indian J Neurosurg 2017;6:83-85.
}

Traumatic optic neuropathy (TON) denotes an acute injury to the optic nerve $(\mathrm{ON})$ secondary to direct or indirect trauma. Direct trauma occurs usually due to penetrating injury causing shearing or hematoma of the ON. Indirect injury results from transmission of forces to optic apparatus after a blunt trauma. ${ }^{1,2}$ The nerve in such injuries is usually injured at the transitions between mobile and fixed (intraorbital and intracanalicular) segments. The most common site of injury is intracanalicular (71.4\%) followed by orbital apex (16.7\%). ${ }^{3} \mathrm{ON}$ is tightly adherent to the dural sheath and periosteum in the intracanalicular portion. This makes it highly susceptible to deformative stresses of the skull bones, during injury. In the intracranial compartment, the most common site of injury is in the anterior cranial fossa, where $\mathrm{ON}$ is in proximity to falciform dural ligament. ${ }^{4}$ Around two-third of TONs are associated with significant head injury, whereas only 2.3\% patients with head injury have TON. Exact incidence of TON in head injury cases is difficult to ascertain as many patients with severe injury die or remain in comatose conditions. However, literature review reveals, reported incidence of $0.4 \%$. Injury is more commonly reported in young males. Approximately $79 \%$ males with a median age of 31 years were reported to have suffered with TON in a series of 121 cases of British Study. ${ }^{5}$ A pediatric study also reported similar findings of $60 \%$ males with mean age of 11.6 years.

Secondary injury to the ON can result from sequelae of acute injury, leading to edema of $\mathrm{ON}$, which can cause retinal ganglion cell degeneration and further decrease in vascularity. Surgical optic canal decompression and use of steroids in such cases may be helpful. Classification for TON is summarized in -Table $\mathbf{1}$.

TON patients usually present with uniocular or binocular decrease in vision following an injury. Initial diagnosis may be delayed in the setting of severe head injury and comatose patients. Therefore, a careful ophthalmologic examination is necessary in all cases of head injury. Presence of hematoma, laceration, raccoon eyes, swelling, and a bony step should be documented. Wherever feasible, visual acuity should be evaluated. In case of comatose patients, presence of relative afferent pupillary defect is a pathognomic finding. This

Address for correspondence Vivek Tandon, MCh, Department of Neurosurgery, All India Institute of Medical Sciences, New Delhi, India (e-mail: drtandonvivek@gmail. com). finding may be absent in symmetrical bilateral TON. Impaired color vision and variable visual field defects may be documented in conscious patients. Fundus examination is necessary. It may reveal ON head swelling and adjacent retinal hemorrhages. It may also help in ruling out preexisting optic neuropathy in acute settings. Presence of normal ON head does not necessarily rule out TON, as optic atrophy findings may appear after 4 to 6 weeks. Approximately $89 \%$ patients of TON were reported to be having normal fundus in a study of 27 patients. ${ }^{6}$

At center, neuroimaging is performed for all cases of suspected TON. Primary investigation of choice in acute settings is computed tomography (CT) scans. It reveals the bony injury and is also helpful in quickly assessing for any intracranial and maxillofacial injuries. ${ }^{7}$ CT is adequate for most penetrating foreign-body injuries, except glass and occasionally wood. Ultrasound may not be useful in an open globe injury. ${ }^{8}$ Doppler study of the central retinal artery has been shown to have altered hemodynamics in $\mathrm{TON}^{9}$ Magnetic resonance imaging (MRI) is contraindicated in cases of metallic (ferromagnetic) penetrating injury. Diffusion tensor imaging can help in delineating TON. ${ }^{10}$

Visual evoked potential (VEP) helps in objectively assessing the ON and visual pathway, particularly in comatose patients or patients with bilateral TON. It is also a useful tool in predicting the prognosis. Absence of VEP portends a poor prognosis. Amplitude within $50 \%$ of normal is considered as favorable. Practical use of VEP in comatose patients is limited

Table 1 Classification of pathology of optic nerve injury

\begin{tabular}{|l|l|}
\hline A. Primary pathology & $\begin{array}{l}\text { - Concussion } \\
\text { - Avulsion or tear } \\
\text { - Contusion } \\
\text { - Hemorrhage } \\
\end{array}$ \\
\hline B. Secondary injury & $\begin{array}{l}\text { - Edraneural/extraneural) } \\
\text { - Ischemia } \\
\text { - Microvascular thrombosis } \\
\text { - Infarction of the nerve }\end{array}$ \\
\hline
\end{tabular}

(C) 2017 Neurological Surgeons' Society License terms of India ()(1) $\Theta \circledast$ 
as shifting of equipment or patients for this test is not always feasible. Moreover, intracranial injuries along the visual pathways may lead to alteration of findings. ${ }^{8,11}$

Optical coherence tomography can show thinning of retinal nerve fiber layer. Its usefulness is limited to documenting the progression, over long-term follow-up. ${ }^{12}$

Treatment of TON is controversial to say the least. Even after multiple approaches being used, prognosis remains guarded for severely injured. Management options range from conservative follow-up to use of steroids or surgical decompression.

We prefer to conservatively follow up all patients with good baseline visual acuity, having no history or surrogate markers of severe head injury. Literature search reveals, that results of conservative follow-up are comparable to use of steroids or surgery or both. ${ }^{8}$

Steroid use in TON was based on its documented usefulness in acute spinal cord injury (SCI). However, many studies, including the NASCIS (National Acute Spinal Cord Injury Study) trials, have failed to prove its efficacy for SCI. A randomized, placebo-controlled, double-blind trial has similarly failed to prove the usefulness of high-dose corticosteroid treatment of recent TON when compared with a placebo. ${ }^{13}$ Similar findings have been reported in two other studies as well. ${ }^{6,14} \mathrm{An}$ animal study in rat has proved the futility of steroid use (high, very high, and megadose of methylprednisolone) by showing that rats with similar injuries, when treated with saline instead of steroids, had higher number of axons and there was a dose-dependent decline with use of steroid. ${ }^{15}$ Side effects of steroids in patients with head injury are detrimental, their usefulness is questionable, and trials have demonstrated increased risk of death. Therefore, we are no more favor high-dose steroid use in TON. At best, level II evidence can only support use of steroids in TON patients who do not have traumatic brain injury (TBI) or any contraindication for steroids (e.g., peptic ulcer, diabetes mellitus, glaucoma, etc.). Maximum permissible dose of $1 \mathrm{~g}$ of methylprednisolone or equivalent should be used. ${ }^{8}$

We recommend surgical decompression to a very select group of patients, where there is definitive evidence to impingement of ON due to a bony fragment or a foreign body. Patients with intraneural and ON sheath hematoma have also been described in literature, who may benefit with surgery. ${ }^{8}$ Apart from these conditions, usefulness of surgery is questionable, as risks far outweigh the benefits. Our observations, over the years, have been corroborated by International Optic Nerve Trauma Study (IONTS). This nonrandomized multicenter trial of 133 patients, treated by conservative/methylprednisolone/surgical basis, has shown that neither of the option is more beneficial when compared with conservative follow-up. Moreover, 57\% patients, who were not treated, showed three or more lines of improvement in visual acuity. ${ }^{16}$

There is no level I evidence to support the usefulness of ON fenestration and opening of annulus of Zinn. Multiple surgical techniques described in literature for surgical decompression are intracranial, endonasal, sublabial, or transethmoidal approaches. These can be performed using microscope or endoscope. Timing of surgery is also controversial. Surgical decompression, when deemed necessary, should be done within 1 week. Endoscopic approach has lesser morbidity, in terms of absence of a visible scar. Optic canal can be accessed above the optic carotid recess by this transnasal-transsphenoidal approach. ${ }^{17-19}$ Prognosis even after this approach remains guarded. A study of 96 patients, in which endoscopic ON decompression was performed, reported an improvement in only $40 \%$ patients, who could read one more line on Snellen's chart. The most important factor was better preoperative visual acuity. ${ }^{20}$ Similar findings along with timing of surgical intervention have been cited as important prognostic factors by other study as well. ${ }^{21}$ Thakar et al have also shown that supplemental incision over ON sheath may be better than osseous decompression alone. ${ }^{2}$

Most important prognostic factor is presence of better visual acuity after injury. Kumaran et. al ${ }^{8}$ have reported that "patients with TON due to indirect injury, having lower grade RAPD and showing signs of visual recovery within 48 hours have a better prognosis."

The reason for poor prognosis, even after use of all available treatment modalities, is inability of central nervous system neuron to regenerate. Moreover, compensatory circuit formation for visual pathway fibers is also questionable. ${ }^{8}$ Thus new research is focusing on drugs that can help in improving neuroprotection and neuroregeneration. There is no level I or II evidence to support use of these newer treatment options. However, usefulness of eythropoeitin, ${ }^{22}$ crystalline, ${ }^{23}$ glutamate inhibitors (lomerizine and minocycline), ${ }^{24}$ brainderived neurotrophic factor, ${ }^{25}$ tacrolimus, ${ }^{26}$ and tissue necrosis factor- $\alpha$ and nitric oxide synthase inhibitors ${ }^{27}$ is being investigated. Therapeutic hypothermia in rats has been shown to be protective, ${ }^{28}$ but its usefulness in humans in view of existing brain trauma foundation guidelines for head injury in itself is questionable. Ocular transplantation in coldblooded vertebrates has led to some recovery, but in mammals it invariably fails due to inability of ganglion cell axons to regenerate. $^{8}$

Based on current literature review and Mahapatra's criteria, ${ }^{11,29}$ our recommendations are summarized as follows:

- All TON patients, who are not having severe TBI or contraindication for steroid use, are given a shortduration course of steroid.

- VEP and clinical examination are repeated every 2 to 3 days for the first 3 weeks.

- Patients showing good recovery are treated conservatively.

- Surgery is indicated in patients in whom visual improvement is marginal and then remains static and cause of compression is discernable. It is preferable to perform surgery within 1 to 2 weeks.

- Emergency surgery is rarely indicated in patients, in whom visual deterioration is delayed in onset and occurs rapidly, even after steroid use.

- Use of newer drugs is not supported by any level I or II evidence. 
Despite all treatment options, prognosis in TON remains guarded. However, protocol-based management and timely intervention in indicated cases may help in salvaging vision of many patients.

\section{References}

1 Steinsapir KD, Goldberg RA. Traumatic optic neuropathy: an evolving understanding. Am J Ophthalmol 2011;151(06):928-933.e2

2 Thaker A, Tandon DA, Mahapatra AK. Surgery for optic nerve injury: should nerve sheath incision supplement osseous decompression? Skull Base 2009;19(04):263-271

3 Anderson RL, Panje WR, Gross CE. Optic nerve blindness following blunt forehead trauma. Ophthalmology 1982;89(05):445-455

4 Crompton MR. Visual lesions in closed head injury. Brain 1970; 93(04):785-792

5 Lee V, Ford RL, Xing W, Bunce C, Foot B. Surveillance of traumatic optic neuropathy in the UK. Eye (Lond) 2010;24(02):240-250

6 Ropposch T, Steger B, Meço C, et al. The effect of steroids in combination with optic nerve decompression surgery in traumatic optic neuropathy. Laryngoscope 2013;123(05):1082-1086

7 Lee HJ, Jilani M, Frohman L, Baker S. CT of orbital trauma. Emerg Radiol 2004;10(04):168-172

8 Kumaran AM, Sundar G, Chye LT. Traumatic optic neuropathy: a review. Craniomaxillofac Trauma Reconstr 2015;8(01):31-41

9 Shi W, Wang HZ, Song WX, Yang WL, Li WY, Wang NL. Axonal loss and blood flow disturbances in the natural course of indirect traumatic optic neuropathy. Chin Med J (Engl) 2013;126 (07):1292-1297

10 Bodanapally UK, Kathirkamanathan S, Geraymovych E, et al. Diagnosis of traumatic optic neuropathy: application of diffusion tensor magnetic resonance imaging. J Neuroophthalmol 2013;33 (02):128-133

11 Mahapatra AK. Visual evoked potentials in optic nerve injurydoes it merit to be mentioned? Indian J Ophthalmol 1991;39 (01):20-21

12 Cunha LP, Costa-Cunha LV, Malta RF, Monteiro ML. Comparison between retinal nerve fiber layer and macular thickness measured with OCT detecting progressive axonal loss following traumatic optic neuropathy. Arq Bras Oftalmol 2009;72(05):622-625

13 Rajiniganth MG, Gupta AK, Gupta A, Bapuraj JR. Traumatic optic neuropathy: visual outcome following combined therapy protocol. Arch Otolaryngol Head Neck Surg 2003;129(11):1203-1206

14 Lee KF, Muhd Nor NI, Yaakub A, Wan Hitam WH. Traumatic optic neuropathy: a review of 24 patients. Int J Ophthalmol 2010;3 (02):175-178

15 Steinsapir KD, Goldberg RA, Sinha S, Hovda DA. Methylprednisolone exacerbates axonal loss following optic nerve trauma in rats. Restor Neurol Neurosci 2000;17(04):157-163
16 Levin LA, Beck RW, Joseph MP, Seiff S, Kraker R. The treatment of traumatic optic neuropathy: the International Optic Nerve Trauma Study. Ophthalmology 1999;106(07):1268-1277

17 Horiguchi K, Murai H, Hasegawa Y, Mine S, Yamakami I, Saeki N. Endoscopic endonasal trans-sphenoidal optic nerve decompression for traumatic optic neuropathy-technical note. Neurol Med Chir (Tokyo) 2010;50(06):518-522

18 Kong DS, Shin HJ, Kim HY, et al. Endoscopic optic canal decompression for compressive optic neuropathy. J Clin Neurosci 2011;18(11):1541-1545

19 Wang DH, Zheng CQ Qian J, Barr JJ, Anderson AG Jr. Endoscopic optic nerve decompression for the treatment of traumatic optic nerve neuropathy. ORL J Otorhinolaryngol Relat Spec 2008;70 (02):130-133

20 Yang QT, Zhang GH, Liu X, Ye J, Li Y. The therapeutic efficacy of endoscopic optic nerve decompression and its effects on the prognoses of 96 cases of traumatic optic neuropathy. J Trauma Acute Care Surg 2012;72(05):1350-1355

21 Peng A, Li Y, Hu P, Wang Q. Endoscopic optic nerve decompression for traumatic optic neuropathy in children. Int $\mathrm{J}$ Pediatr Otorhinolaryngol 2011;75(08):992-998

22 Acar U, Kucuk B, Sevinc MK, Aykas S, Erdurmus M, Sobaci G. Intravitreal erythropoietin injection in late-stage optic neuropathy: a safety study on human. Int Ophthalmol 2017. [ Epub ahead of print ]

23 Wu N, Yin ZQ, Wang Y. Traumatic optic neuropathy therapy: an update of clinical and experimental studies. J Int Med Res 2008; 36(05):883-889

24 Fitzgerald M, Payne SC, Bartlett CA, Evill L, Harvey AR, Dunlop SA. Secondary retinal ganglion cell death and the neuroprotective effects of the calcium channel blocker lomerizine. Invest Ophthalmol Vis Sci 2009;50(11):5456-5462

25 Chen $\mathrm{H}$, Weber AJ. BDNF enhances retinal ganglion cell survival in cats with optic nerve damage. Invest Ophthalmol Vis Sci 2001; 42(05):966-974

26 Que J, Cao Q, Sui T, Du S, Kong D, Cao X. Effect of FK506 in reducing scar formation by inducing fibroblast apoptosis after sciatic nerve injury in rats. Cell Death Dis 2013;4:e526

27 Tezel G, Yang X, Yang J, Wax MB. Role of tumor necrosis factor receptor-1 in the death of retinal ganglion cells following optic nerve crush injury in mice. Brain Res 2004;996(02): 202-212

28 Matthews KA, Kunte AS, Tambe-Ebot E, Rawson RB. Alternative processing of sterol regulatory element binding protein during larval development in Drosophila melanogaster. Genetics 2009; 181(01):119-128

29 Mahapatra AK. Visual problems following head injury. In: Mahapatra AK, Kamal R, eds. Textbook of Head Injury. 4th ed. New Delhi, India: CBS Publishers and Distributors; 2014:462-473 